\title{
Towards achieving Sustainability of coastal environments: Urban Growth analysis and prediction of Lagos, State Nigeria
}

\author{
Temitope Ezekiel Idowu ${ }^{1,3}$, Rose Malot Waswa ${ }^{2}$, Kayode Lasisi ${ }^{3}$, Kenneth Mubea ${ }^{2}$, Maurice \\ Nyadawa $^{4}$, John Bosco Kyalo Kiema ${ }^{2}$
}

\begin{abstract}
${ }^{1}$ Faculty of Engineering and the Built Environment, Technical University of Kenya, P.O Box 5242800200, Nairobi Kenya. Email. lois.temitope@gmail.com

${ }^{2}$ Regional Centre for Mapping of Resources for Development, Nairobi, Kenya

${ }^{3}$ Sanbid-Kay Engineering Services, Akure, Nigeria

${ }^{4}$ Pan African University- Institute for Basic Science Technology \& Innovation, at the Jomo Kenyatta University of Agriculture and Technology Main, Juja, Kenya.
\end{abstract}

\begin{abstract}
The most extensive urban growths in the next 30 years are expected to occur in developing countries. Lagos, Nigeria - Africa's second most populous megacity-is a prime example. To achieve more sustainable and resilient cities, there is a need for modeling the urban growth patterns of major cities and analyzing their implications. In this study, the urban growth of Lagos state was modeled using the Multi-Layer Perceptron (MLP) neural network for the transition modeling and the Markov Chain analysis for the change prediction, achieving a model accuracy of $81.8 \%$. An innovative visual validation of the model results using the ArcGIS was combined with kappa correlation statistics. The results show that by 2031, built-up areas will be the most spatially extensive LULC class in the study area with percentage coverage of $34.1 \%$ as opposed to $9 \%$ in 1986. The coverage of bare areas is also expected to increase by $53 \%$ between 2016 and 2031. Conversely, 24.9\% and 68.3\% loss of forestlands and wetlands respectively, are expected between 2016 and 2031. In view of the $11^{\text {th }}$ goal of SDGs which focuses on achieving sustainable cities and communities, the objectives of African Union's Agenda 2063, and based on the urban growth trends observed, the study recommends a prioritization of vertical expansion as opposed to the current horizontal urban growth trends in the study area.
\end{abstract}

Keywords: Urbanization growth prediction; Sustainable development, Land Change Modeler; IDRISI Selva; Land use land cover; Coastal cities; Lagos; Markov Chain; Multi-Layer Perceptron; Sustainability; Agenda 2063. 


\subsection{Introduction}

A century ago, only $20 \%$ of the global population resided in urban areas, but this is projected to reach $70 \%$ by the year 2050 (WHO 2010). Globally, the most extensive urban growths between 2014 and 2050 will occur in developing countries, and the leading country is Nigeria (United Nations 2014). It currently experiences the $3^{\text {rd }}$ highest urban growth rate in the world and urban dwellers are projected to reach 212 million by 2050 (United Nations 2014)- a double-fold increase from slightly over 100 million in 2019 (Worldometers 2019).

Coastal cities are of greater concern due to their significant roles as hubs of international commerce. Hence, coastal cities in many parts of the world experience a relatively higher population and urban growth rates than the national average trends (Wong et al. 2014). Three of the megacities (with population > 10 million) to emerge in Africa by 2030, - Lagos, Luanda, and Dar es salam -, are coastal (UNDESA 2018). The population increase experienced by these coastal cities, coupled with climate change-related events aggravate coastal challenges like seawater intrusion and groundwater contamination (Ezekiel et al. 2016, Idowu et al. 2017), coastal flash floods (Ajibade et al. 2013), urban sprawls (Li et al. 2016), land subsidence (Showstack 2014) amongst others. These challenges necessitate deliberate and proactive management plans for sustainable development. The Sustainable Development Goals (SDGs) 11 emphasizes the need for proactive actions towards ensuring "Sustainable Cities and Communities by making cities safe, inclusive, resilient, and sustainable" (UN 2017). One of the pivotal steps towards achieving this target is the generation of empirical knowledge on spatial changes in land use land cover and the observation of the transformation of these cities (McPhearson et al. 2016).

The number of land cover predictive models has increased rapidly in the last two decades because they have been found valuable for urban planning and environmental management (Kumar et al. 2015, Giri 2012). The predictive models aid a better understanding of the complex systems and invariably support land use planning and policy decisions (Megahed et al. 2015). Verburg et al., (2004) highlights the six important concepts in land use modeling- Level of analysis; Level of integration; Spatial interaction and neighborhood driving forces; Crossscale dynamics; Temporal dynamics; and driving forces, model types, and model implementation. The characteristics of some of the models are also reported in Verburg, et al., (2004) and Table 1 highlights recently used LULC change prediction models and their applications. The paper combined the modeling capabilities of the Land Change Modeler (LCM) in IDRISI with the spatial capabilities of the ArcGIS software to assess the urban growth trend in the study area. 
The Land Change Modeler (LCM) is a component of an ensemble software platform IDRISI (Eastman 2012). IDRISI Selva (version 17), with faster processes and additional tools in comparison to previous versions of the software (Clark Labs 2012). This paper 1) explores the effectiveness of a loose coupling of LCM with the ArcGIS for predicting the urban growth change of coastal cities and links the results with sustainable development goals, and 2) identifies some current challenges inherent in the use of the LCM prediction model and areas requiring improvements. Integrating the LCM and ArcGIS platforms has two advantages; 1) the LCM can also be utilized as an extension to ArcGIS and 2) ArcGIS has the capability to summarize LULC areas based on the number of pixels, generate tables and export to excel which is not currently achievable with the LCM in IDRISI.

Table 1. Predictive models currently in use and their applications

\begin{tabular}{|c|c|c|c|}
\hline Model & Study Area & Land change application & References \\
\hline $\mathrm{MC}-$ & Su-Xi-Chang region, China, & LULC prediction for Ecosystem & (Yirsaw et al. 2017) \\
\hline $\mathrm{CA}^{1}$ & Harbin prefecture, China & Services & (Gong et al. 2015) \\
\hline $\mathrm{LCM}^{2}$ & Asmara, Eritrea, Cairo Egypt & Urban growth prediction & $\begin{array}{l}\text { (Tewolde \& Cabral 2011) } \\
\text { (Megahed } \text { et al. 2015) }\end{array}$ \\
\hline LTM-MC & $\begin{array}{l}\mathrm{SEWI}^{3}, \& \mathrm{MRW}^{4}, \text { Michigan, } \\
\text { USA }\end{array}$ & Modeling multiple Land cover types & (Tayyebi \& Pijanowski 2014) \\
\hline SLEUTH $^{5}$ & Rajasthan (India) & Urban growth prediction & (Jat et al. 2017) \\
\hline CLUE $^{6} \&$ & Farmlands in Europe, & Modeling future dynamics of Land & (Verburg \& Overmars 2009) \\
\hline$\frac{\text { CLUE-S }}{1 \mathrm{M}}$ & $\begin{array}{l}\text { Romania } \\
\text { CA: Markov Chain-Cellular Auton }\end{array}$ & $\begin{array}{l}\text { use and cover types } \\
\text { 2 LTM-MC: Land Transformation Model-N }\end{array}$ & $\begin{array}{l}\text { (Grigorescu et al. 2019) } \\
\text { ltiple Classifications; } 3 \text { SEWI: South }\end{array}$ \\
\hline
\end{tabular}

\subsection{Study area}

Lagos is a coastal megacity located slightly above the equator in southwest Nigeria (Fig. 1) and is one of three megacities in Africa alongside Cairo and Kinshasa (UNDESA 2018). It is currently the second most populous city on the continent (after Cairo) with a population growth rate of $6-8 \%$ per annum which is more than twice the national average of $2.6 \%$ per annum (UNDESA 2018, The World Bank 2019). It is a low lying coastal plain, characterized by a flat topography with notable geographical features such as; the mainland, lagoon, creeks, wetlands, seaports, several small Islands, and reclaimed lands such as the Banana Island and Eco Atlantic City. Although it is the most populous state in Nigeria, its $3,577 \mathrm{~km}^{2}$ land area is only about $0.4 \%$ of the country's landmass (MPPUD 2016). Urbanization expressed as the outward expansion of built-up areas and the conversion of primary agricultural and forestlands into industrial and residential uses (Opoko et al., 2014), and land reclamation activities are visibly evident in Lagos Nigeria (Idowu \& Home 2015).

Lagos state's status and relevance as the "commercial, business, and financial hub of Nigeria and sub-Sahara Africa(MPPUD 2016) makes it a pivotal point of reference for the African Union's 2063 Agenda to become more prosperous through sustainable development and 
all-inclusive growth (African Union Commission 2015). The success of the agenda is contingent upon the effective management of the urban growth of its cities and megacities.

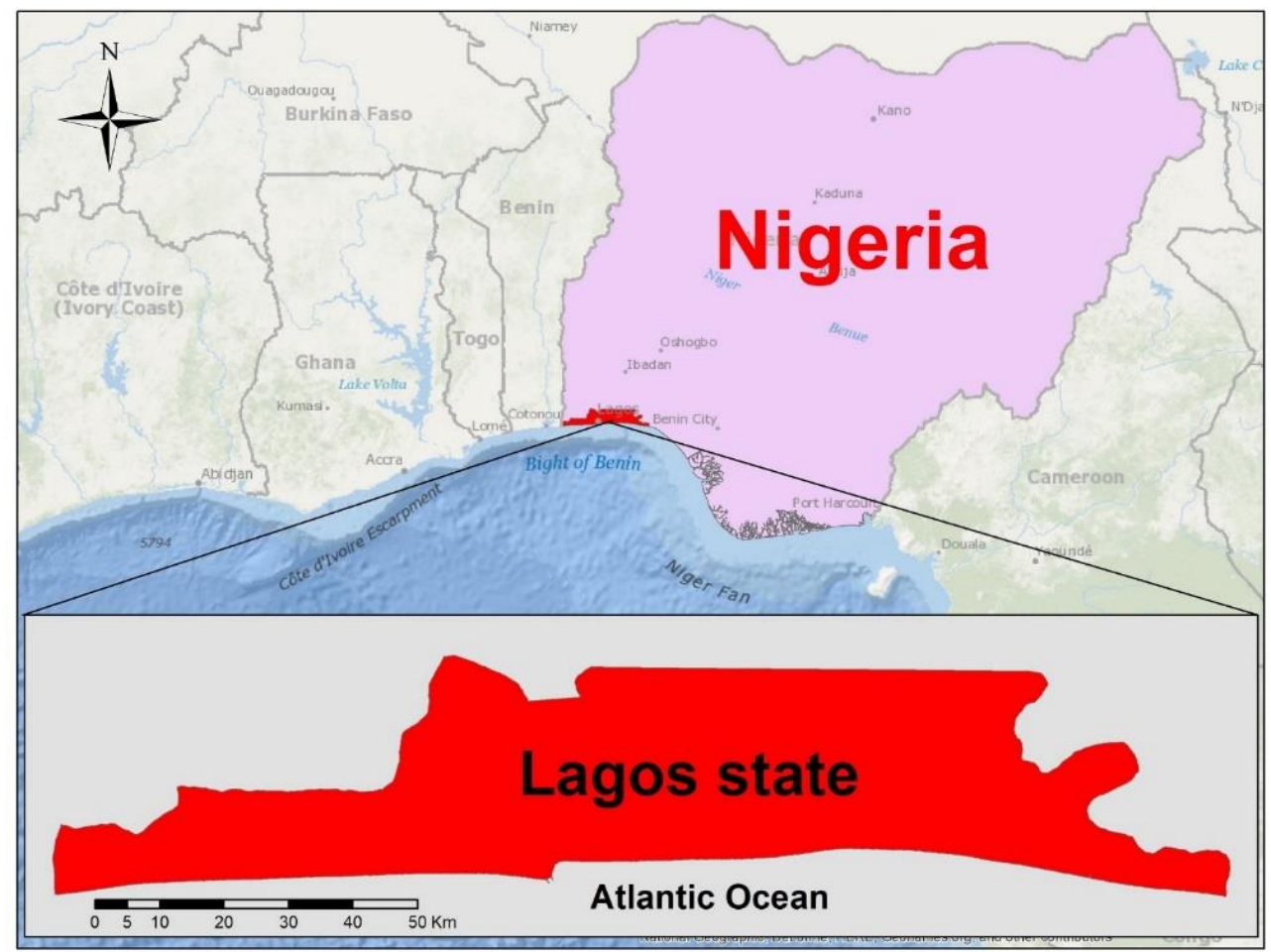

Figure 1. Location map of Lagos, Nigeria.

\subsection{Methodology}

\subsection{Data}

Landsat Thematic Mapper (TM) and Enhanced Thematic Mapper Plus (ETM+) images were obtained for the years 1986 and 2001 while multi-sensor SENTINEL 2A data was acquired for the year 2016. The years were chosen based on the availability of cloud-free images at 15 years intervals. The images were obtained from the United States Geological Survey's portal (USGS 2020) and the Copernicus Open access hub (ESA 2020). The ancillary data such as the Digital Elevation Model (DEM) and the road layers were downloaded from the United States Geological Survey and Geofabrik platforms respectively (USGS 2017, Geofabrik 2017). All datasets were in the World Geodetic System (WGS) 1984, UTM Zone 31N coordinate system.

\subsection{Methods}

An object-based image analysis and post-classification comparison were performed on the multi-temporal datasets for the three years - 1986, 2001, and 2016- to obtain the LULC maps of each year (Idowu et al. 2020). The maps contain six LULC classes- bare areas, built-up areas, 
forestlands, shrublands, waterbodies, and wetlands, according to the CORINE classification nomenclature as described in an earlier study (Idowu et al. 2020). The TIFF formats of the 1986 and 2001 LULC maps were subsequently imported into IDRISI where they were first converted into RST before uploading on the Land Change Modeler. The comparative LULC changes were analyzed and subsequently, the transition potentials and sub-models were generated, forming the basis for creating the predicted 2016 LULC by the model. The model's accuracy was assessed by validating the predicted 2016 with the actual 2016 LULC map. Once validated, the model was used to predict urban growth by the year 2031. Figure 2 gives an overview of the steps taken in the modelling process.

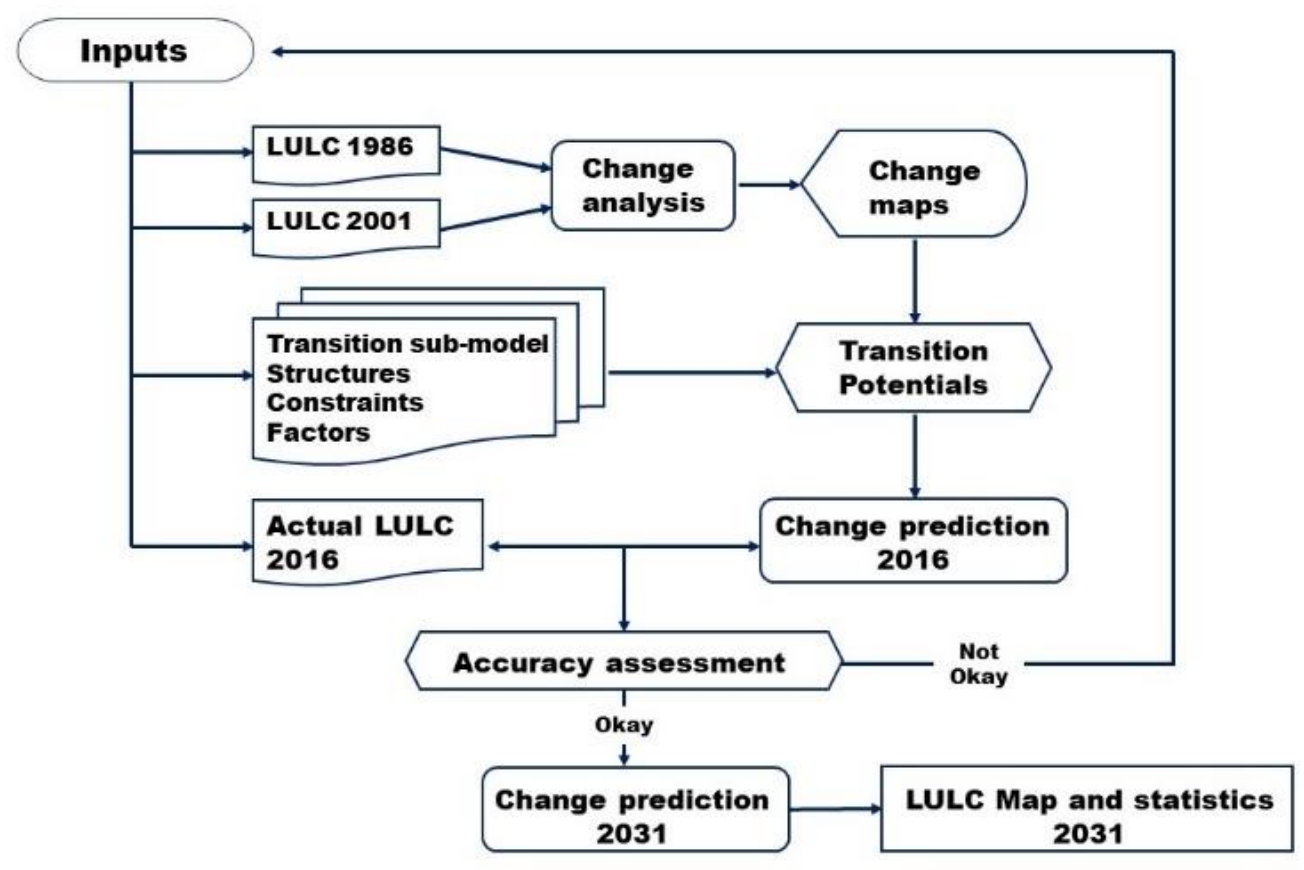

Figure 2. Methodology flowchart for the urban growth prediction

\section{LCM Model Implementation}

The model's four major procedures which include; Change analysis; transition potential modeling and driving forces determination; change prediction; and model validation are well detailed by Eastman, (2012).

\section{Change analysis}

The changes being investigated include gains and losses in each LULC class, the net changes in each class, and the contributors to those changes. At this stage, the analyzed changes in the LULC between the 1986 and 2001 maps helped identify transitions from one land cover type to another. The process was crucial in identifying the dominant transitions contributing to urbanization which formed the basis for the resulting transition sub-models created. It was 
observed in previous studies that one of the major drivers of land-use change in Lagos, Nigeria is accessibility (Braimoh \& Onishi 2007). Hence, ancillary data - DEM and road layers- were entered to account for the impact of topography and road development on possible urban growth. These data act as structures and factors for guiding the creation of the transition sub-models.

\section{Transition potential modeling and driving forces determination}

The transition potential modeling helps to determine the location of the change, and it results in the generation of transition potential maps (Eastman 2012). The driver variables are either static or dynamic and natural or anthropogenic driven. In this study, the dominant driving force was urbanization induced by an increase in population and evidenced by the transition of other land cover categories into built-up and bare areas. One of the challenges encountered in LULC change prediction is the need to account for the dynamic nature of land cover change where the different land cover types transition into each other simultaneously. The multi-layer perceptron (MLP) neural network module in the LCM addresses the challenge in that it can model multiple transitions into a single sub-model. Therefore, the MLP was used to model the transitions and develop the transition sub-models in this study. In ensuring optimum accuracy of the transition sub-models, the variable transformation utility (VTU), based on evidence likelihood transformations was run to address issues of non-linearity in the transition sub-model. The Cramer's V obtained from the VTU is a correlation coefficient ranging from 0.0 to 1.0 indicating no and perfect correlation, respectively (Eastman 2012). Cramer's V does not necessarily imply a high performance, but it acts as a guide in determining if a driving force is worth considering or not (Khoi \& Murayama 2010, Eastman 2012).

\section{Change prediction}

The predicted change in each transition was modeled using the Markov chain analysis. Markov Chain is a random procedure that measures the expected transitions to the predicted date based on the projections of the transition potentials (Mishra et al. 2014). The two basic models of change- the hard and soft prediction models were obtained. The hard prediction yields LULC maps with discrete values and similar legends to the input maps while the soft produces a vulnerability map with continuous pixel values of probability of change from 0 to 1 .

\section{Model validation/accuracy assessment}

The two broad types of validation are visual and statistical validations. The VALIDATE module in the LCM, a visual validation process was used to analyze the degree of agreement between the reference (actual) and the predicted 2016 maps by generating a map of correctness and error. Statistical validation is based on Kappa correlation statistics. These statistics include $\mathrm{K}_{\mathrm{no}}, \mathrm{K}_{\text {location, }}$ and $\mathrm{K}_{\text {standard, }}$ where $\mathrm{K}_{\mathrm{no}}$ reflects the overall accuracy of the simulation run; $\mathrm{K}_{\text {location }}$ 
measures the level of agreement of location and $\mathrm{K}_{\text {standard }}$ is the ratio of the proportion assigned correctly to the proportion which is correct by chance (Tewolde \& Cabral 2011, Megahed et al. 2015). Some predictive studies employed the statistical approach only (Feng et al. 2016, Hamdy et al. 2016), while some utilized the visual validation method only (Mahmoud et al. 2016). Few studies adopted both approaches but were not elaborate with the detailed steps taken (Megahed $e t$ al. 2015). This study combined both and went further by using the ArcGIS to analyze the map of correctness and error to determine the Hits, Null success (persistence), Misses, and False alarms. Hits and persistence represent the correctness of the predicted map while the misses and false alarms represent the discrepancy between the predicted map and the actual map (Megahed et al. 2015). Once the visual and statistical validations were found satisfactory, the model was used to predict the LULC map of 2031.

\subsection{Results}

The results of the hard prediction which yields discrete values like the LULC input maps show that from 2016 to 2031, the LULC is likely to undergo drastic changes towards massive urbanization and deforestation (Table 2). Increases in bare areas which may be due to land reclamation activities and built-up areas are direct indicators of urbanization. On the other hand, the losses in forestland and gradual increase in shrublands - areas dominated by low lying plants with few scattered trees such as agricultural lands and developing areas- are pointers to deforestation.

Over 30\% (>28,000ha) and 50\% (>17,000ha) increases in built-up and bare areas, respectively are expected between 2016 and 2031 (Table 2). There may be wetland losses of almost $70 \%$ (>600ha), while further deforestation (over 35,000ha loss) may occur in the same period.

Table 2: Comparison of the LULC Maps in 1986, 2001, 2016 and the predicted 2031 map

\begin{tabular}{l|cc|c|c|cc|cc}
\hline LULC CLASS & $\mathbf{1 9 8 6}$ & $\mathbf{2 0 0 1}$ & $\mathbf{2 0 1 6}$ & \multicolumn{2}{|c|}{$\mathbf{2 0 3 1}$} & \multicolumn{2}{|c}{ Changes $(\mathbf{2 0 1 6}$ to 2031) } \\
\cline { 6 - 9 } & $\mathbf{H a})$ & $\mathbf{( \% )}$ & $\mathbf{H a})$ & $(\mathbf{H a})$ & $\mathbf{H a})$ & $\mathbf{( \% )}$ & $\mathbf{( H a )}$ & $\mathbf{( \% )}$ \\
\hline Bare Area & 627.2 & $\mathbf{0 . 2}$ & $1,423.9$ & $3,313.4$ & 5068.1 & $\mathbf{1 . 4}$ & 1754.8 & $\mathbf{5 3}$ \\
Built Up Area & 32,200 & $\mathbf{9 . 0}$ & $59,878.6$ & $93,113.2$ & $121,918.5$ & $\mathbf{3 4 . 1}$ & $28,805.3$ & $\mathbf{3 0 . 9}$ \\
Forestland & $227,390.6$ & $\mathbf{6 3 . 6}$ & $189,426.6$ & $143,848.8$ & $108,086.9$ & $\mathbf{3 0 . 2}$ & $-35,761.9$ & $\mathbf{- 2 4 . 9}$ \\
Shrubland & $13,653.8$ & $\mathbf{3 . 8}$ & $24,375.8$ & $36,914.7$ & $43,274.3$ & $\mathbf{1 2 . 1}$ & 6359.7 & $\mathbf{1 7 . 2}$ \\
Waterbody & $81,621.9$ & $\mathbf{2 2 . 8}$ & $80,773.5$ & $79,647.8$ & $79,098.2$ & $\mathbf{2 2 . 1}$ & -549.6 & $\mathbf{- 0 . 7}$ \\
Wetland & $2,235.5$ & $\mathbf{0 . 6}$ & $1,849.7$ & 890,1 & 282 & $\mathbf{0 . 1}$ & -608.1 & $\mathbf{- 6 8 . 3}$ \\
\hline TOTAL & $\mathbf{3 5 7 , 7 2 8}$ & $\mathbf{1 0 0}$ & $\mathbf{3 5 7 , 7 2 8}$ & $\mathbf{3 5 7 , 7 2 8}$ & $\mathbf{3 5 7 , 7 2 8}$ & $\mathbf{1 0 0}$ & & \\
\hline
\end{tabular}

NB: Ha $=$ Hectares; $\%$ = percentages

The waterbodies in the study area mainly comprise the lagoon and the creeks found in different parts of Lagos state. The progressive losses (although $<1 \%$ ) over the years can be attributed to the land reclamation activities and widespread floating informal settlements 
sprawled on these water bodies. The LULC in 2016 and the predicted LULC map by the year 2031 are represented in Fig. 3.

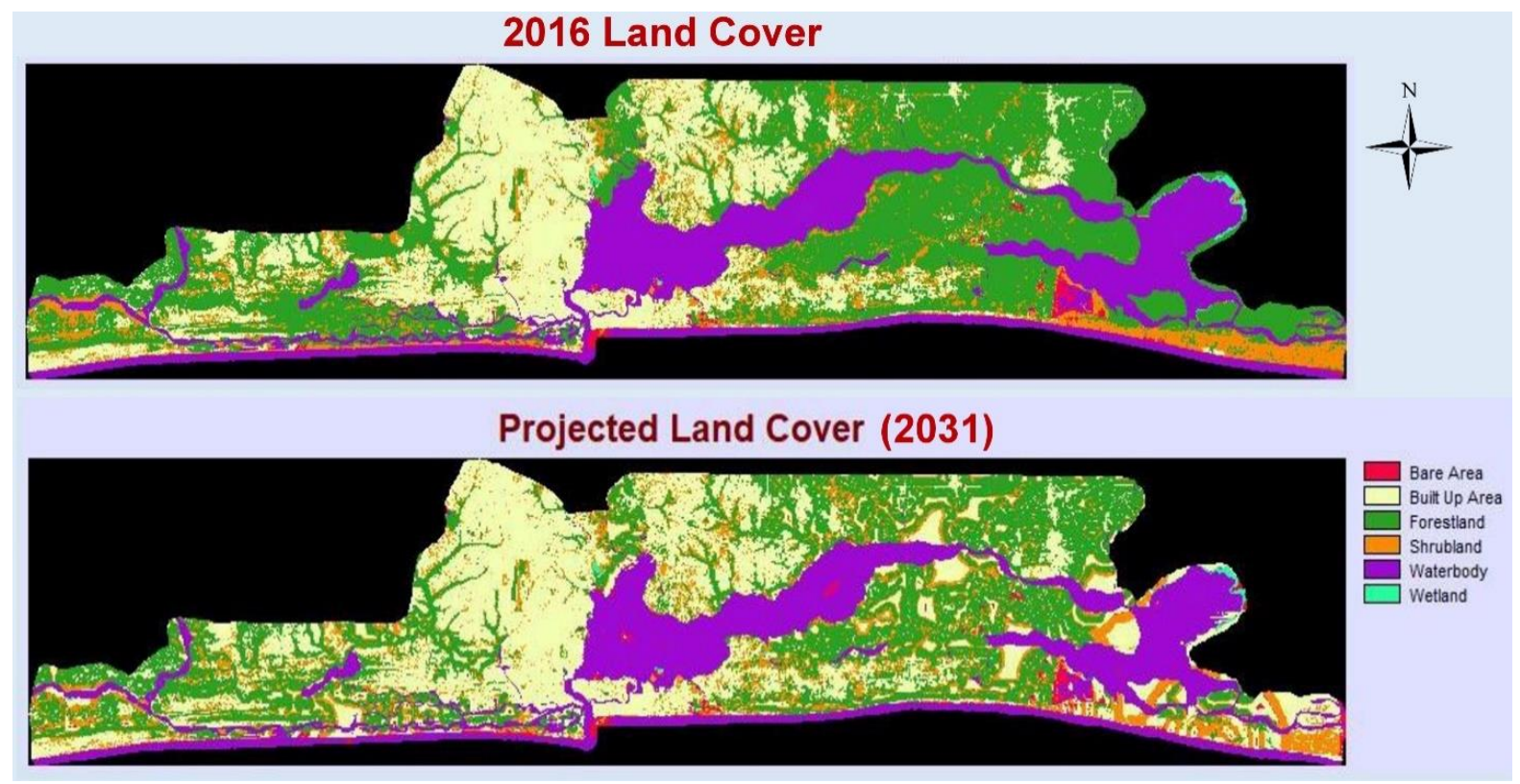

Figure 3. The LULC Maps for 2016 and the predicted 2031

The prediction results indicate that by 2031, built-up areas will likely have surpassed forestlands and waterbodies as the most extensive LULC coverage in the study area at 121,918.5ha (about 34\%). To put that in perspective, built-up area coverage was only $9 \%$ $(32,200 \mathrm{ha})$ of the total land cover in 1986 . In contrast, massive deforestation $(>35,000 \mathrm{ha}$ loss) may occur in the same period with a decrease from 143,848.8ha (40\%) to 108,086.9 (30\%). When Fig 3 is compared with actual administrative maps, the projected urban growth trend are evident in areas such as the Badagry axis; areas along the Lagos - Badagry express road including Agbara; Ikorodu / Ibese axis and areas along the Ikorodu - Epe road; areas along Lekki - Epe express road; and the Lekki lagoon's environs.

Therefore, as with the changes observed between 1986 and 2016, the model predicts that between 2016 and 2031 there will be net gains in shrublands, built-up and bare areas, massive losses of forestlands and wetlands, and slight losses in waterbody areas (Figure 4). The most significant gains and losses between 1986 and 2016 were built-up areas and forestlands, respectively (Fig. 4a) and this trend is likely to continue (Fig 4b) but the rapid losses in forestlands to other LULC classes will contribute to the emergence of built-up areas as the most spatially extensive land cover type by 2031 (Table 2). Built-up and bare area coverage may give a combined coverage of $126,986.6$ ha which is about $35.5 \%$ of the entire LULC of the study area. Fig. 5 shows the contributions to the transitions into each LULC class with Fig. 5a showing that the losses of forestlands will largely be to built-up areas, followed by shrublands and bare areas. 
These gains in built-up areas, shrublands, and bare areas at the expense of the forestland are clear indicators of rapid urbanization and it is also reflected in Fig. $5 \mathrm{c}$ where the main contributor to built-up areas are forestlands, shrublands, and bare areas. Also, the possible losses in waterbodies are due to an increase in built-up and bare areas (Fig. 5d).
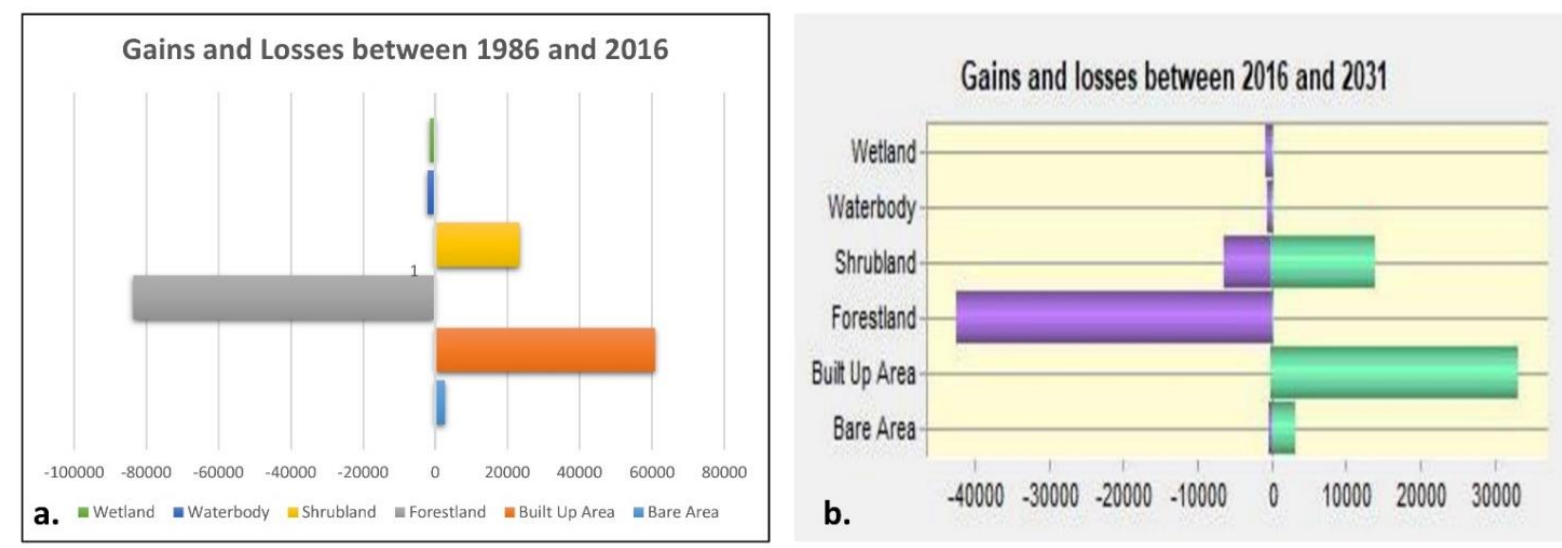

Figure 4. Gains and losses in the LULC Classes between a) 1986 and 2016; b) 2016 and 2031
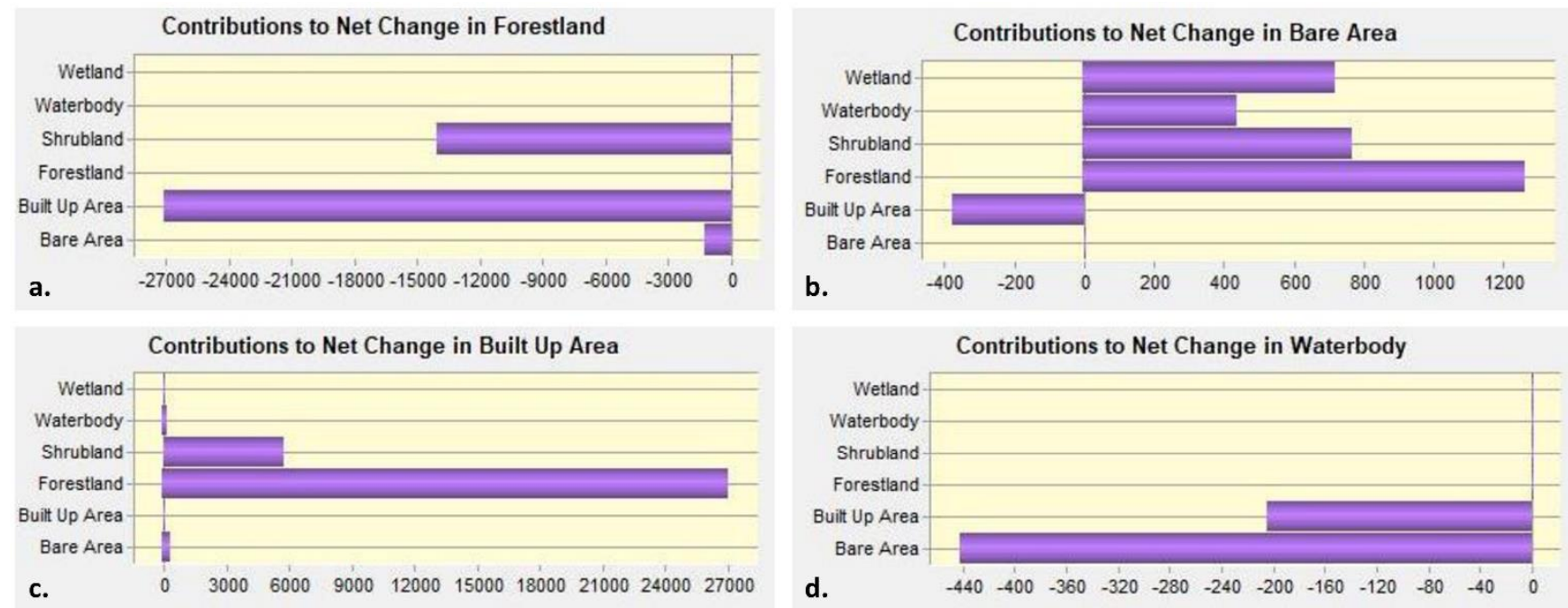

Figure 5. Contributors to the net changes in (a) Forestlands (b) Bare areas; (c) Built-up areas; (d) Waterbodies in Lagos from 2016 to 2031 (in Hectares).

\section{Transition potential sub-model and model validation}

An overall Cramer's V of 0.53 and 0.55 were obtained for 1986 - 2001 and 2001 - 2016, respectively. Cramer's V of over 0.4 is considered highly suitable (Eastman 2012). Values ranging between 0.50 and 0.97 were observed for wetlands, forestlands, shrublands, and waterbodies. It suggests that these LULC classes experienced sizeable transitions into built-up areas during the period under study. The model's accuracy was $81.84 \%$ (>80\%) with training and testing errors of 0.1537 and 0.1539 , respectively. The ArcGIS-based results of the map of correctness and error showed predicted map correctness of $71.4 \%$ (hits and persistence), while 
the misses and false alarms were $13.0 \%$ and $15.6 \%$ respectively. The statistical validation yielded high accuracy values of $80 \%, 84 \%$, and $77 \%$ for the $\mathrm{K}_{\mathrm{no}}, \mathrm{K}_{\text {location, and }} \mathrm{K}_{\text {standard }}$ kappa values, respectively.

\subsection{Discussion}

Urban growth modeling in Lagos state is only just evolving. The earliest study on urban growth modeling in the study area was focused on the viability of cellular automata (CA) for simulating urban growth (Barredo et al. 2004). The more recent urban growth modeling and prediction study by Eyoh et al., (2012) only focused on Lagos metropolis and not the entire study area by loosely coupling a logistic regression model in MATLAB with the ArcGIS. This paper goes further by modeling the urban growth of the entire Lagos state using the Multi-Layer Perceptron (MLP) neural network for the transition modeling and the Markov Chain analysis for the change prediction on the LCM. The $81.84 \%$ model accuracy and kappa correlation statistics of $80 \%, 84 \%$, and $77 \%$ for the $\mathrm{K}_{\mathrm{no}}, \mathrm{K}_{\text {location, and }} \mathrm{K}_{\text {standard }}$ values, obtained between the predicted and reference maps in this study are relatively higher than that of earlier studies. For instance, a Kappa Statistics value of $0.6998(69.98 \%)$ was obtained between the reference and predicted map Eyoh et al., (2012) while $k$-statistic values ranging from 0.63 to 0.88 and an average value of 0.77 were obtained for the land cover classes in Barredo et al., (2004).

However, the findings of both studies show an upward trend in urban growth. For instance, Barredo et al., (2004) predicted a $116 \%$ increase in informal settlements between the years 2000 and 2020, and similarly, Eyoh et al., (2012) predicted an urban expansion of 129.49\% between 1984 and 2030. Similarly, this paper shows that built-up areas represented 32,200ha in 1986, stood at 93,113.2ha in 2016, and is projected to reach 121,918.5ha by 2031 implying an increase of well over $200 \%$ in built-up areas (bare areas excluded). The study also shows that the transformation into urban areas will be more pronounced in the rapidly developing areas outside the metropolis. This confirms a cross-boundary study by Wang and Maduako, (2018) where it was concluded that over $75 \%$ of the urban growth expected between 2015 and 2030 will occur in neighboring Ogun State. However, other parts of the country showed relatively lower urban growth rates such as Akure - 53.41\% increase between 2014 and 2034 (Owoeye \& Popoola 2017); Ibadan Northwest - a combined 19\% increase in bare, built-up and shrublands and a combined 25\% loss in thick forest, waterbodies, and wetlands between 2000 and 2021 (Adebola et al. 2015); and Greater Port Harcourt - an 80\% increase in urban areas between 2003 and 2060 (Dan-Jumbo et al. 2018).

Finally, while carrying out the modeling exercise, the major challenge observed in the IDRSSI-based LCM is its limited compatibility, as it only accepts TIFF raster files, therefore, the 
interaction between the stand-alone software and other software platforms is not yet seamless and needs improvement. Overall, the high model accuracy obtained in this study demonstrates the effectiveness of the loose coupling of LCM and ArcGIS while the findings shows the strong need for sustainable land use management to forestall further deforestation, losses of wetlands, and the effective management of the health and livelihoods of the burgeoning population.

\subsection{Conclusion}

This study focused on the urban growth prediction in the study area by the year 2031 . Between 1986 and 2016, there were net increases in bare areas, built-up areas, and shrublands, and a general decline in forestlands, waterbodies, and wetlands. The urban growth modeling shows that these trends are likely to continue into 2031 except drastic and proactive measures are taken. According to the analyses, bare and built-up areas will increase by 1754.8 ha (53\%) and 28,805.3ha (31\%), respectively between 2016 and 2031. On the other hand, a wetland loss of 608.1 ha $(68.3 \%$ loss $)$ should be expected. These do not only have socioeconomic implications but also ecological. Also, by achieving high model accuracy (>80\%) and kappa statistics $(>75 \%)$, the study demonstrates the effectiveness of loosely coupling the LCM (using the MultiLayer Perceptron (MLP) neural network for the transition modeling and the Markov Chain analysis for the change prediction) with the ArcGIS for LULC Map statistics estimation. However, the quality and reliability of the outputs of current models can still be improved by introducing more input data. Nevertheless, since this study provides insights on the trends in urbanization, it will contribute to the achievement of goal 11 of SDGs which focuses on achieving sustainable cities and communities. At the continental level, the achievement of African Union's Agenda 2063- a 50year development plan geared towards creating a dependent and prosperous Africa (African Union Commission 2015)- will be hinged on timely and accurate predictive information data. Hence, this study's findings can be incorporated while making infrastructural plans for the next decade as it provides pointers to where possible expansions will be concentrated. Finally, to curtail the potentially massive deforestation $(>35,000 \mathrm{ha})$, which is largely at the expense of the gains in built-up areas, it is recommended that vertical expansion in the form of high-rise green buildings be prioritized as against the horizontal urban growth and urban sprawl trend currently being experienced.

\section{Acknowledgments}

The authors acknowledge the Regional Centre for Mapping of Resources for Development (RCMRD) for providing access to the software packages and data used for this study. All thanks to Oluwseun Somefun, Niyi Glory Bass, and Margaret Abiola for their immense assistance all through the data collection and ground-truthing phase of the project. Finally, the authors 
appreciate the staff and management of Jomo Kenyatta University of Agriculture and Technology (JKUAT) and RCMRD for providing the platforms to present and improve the work.

\section{References}

Adebola, AO, Adegboyega, SA, Olajuyigbe, AE, \& Oladejo, SO 2015, 'Modelling of land use and land cover in Ibadan North-West local government area (LGA), Nigeria using satelite imageries and GIS techniques', Journal of Sustainable Development in Africa, vol. 17, no. 7, pp. 138-166.

African Union Commission 2015, Agenda 2063: The Africa We Want, Addis Ababa.

Ajibade, I, McBean, G, \& Bezner-Kerr, R 2013, 'Urban flooding in Lagos, Nigeria: Patterns of vulnerability and resilience among women', Global Environmental Change, vol. 23, no. 6.

Barredo, I, Demicheli, L, Lavalle, C, Kasanko, M, \& Mccormick, N 2004, 'Modelling future urban scenarios in developing countries: an application case study in Lagos, Nigeria', Environment and Planning B: Planning and Design, vol. 32, pp. 65-84, <http://www.envplan.com/epb/fulltext/b31/b29103.pdf>.

Braimoh, AK \& Onishi, T 2007, 'Spatial determinants of urban land use change in Lagos, Nigeria', Land Use Policy, vol. 24, no. 2, pp. 502-515.

Clark Labs 2012, Land Change Modeling for REDD: Reducing Emissions from Deforestation and Forest Degradation, viewed 1 September 2018, <http://www.redd-gis.org/>.

Dan-Jumbo, N, Metzger, M, \& Clark, A 2018, 'Urban Land-Use Dynamics in the Niger Delta: The Case of Greater Port Harcourt Watershed', Urban Science, vol. 2, no. 4, p. 108.

Eastman, JR 2012, 'IDRISI Selva Manual’, IDRISI Selva Manual, , no. January, pp. 1-324.

ESA 2020, Sentinel Open Access Hub, European Space Agency, <https://sentinel.esa.int/web/sentinel/sentinel-dataaccess>.

Eyoh, A, Olayinka, D, Nwilo, P, Okwuashi, O, Isong, M, \& Udoudo, D 2012, 'Modelling and Predicting Future Urban Expansion of Lagos , Nigeria from Remote Sensing Data Using Logistic Regression and GIS', International Journal of Applied Science and Technology, vol. 2, no. 5, pp. 116-124.

Ezekiel, IT, Maurice, N, \& Maurice, K 2016, 'Seawater Intrusion Vulnerability Assessment of a Coastal Aquifer : North Coast Of Mombasa, Kenya as a Case Study', Int J Eng Res Appl, vol. 6(8), pp. 37-45.

Feng, Y, Liu, M, Chen, L, \& Liu, Y 2016, 'Simulation of Dynamic Urban Growth with Partial Least Squares Regression-Based Cellular Automata in a GIS Environment', ISPRS International Journal of GeoInformation, vol. 5, no. 12, p. 243, 〈http://www.mdpi.com/2220-9964/5/12/243〉.

Geofabrik 2017, Africa- Open Street Map data, viewed 15 May 2017, <http://download.geofabrik.de/africa.html>.

Giri, CP 2012, 'Remote sensing of land use and land cover: principles and applications', ICRC Press, vol. 1161, no. August, pp. 1-469, <http://environmental-science-and-engineering.crcpress.com/new-notable/remotesensing-of-land-use-and-land-cover-principles-and-applications/>.

Gong, W, Yuan, L, Fan, W, \& Stott, P 2015, 'Analysis and simulation of land use spatial pattern in Harbin prefecture based on trajectories and cellular automata-Markov modelling', International Journal of Applied Earth Observation and Geoinformation, vol. 34, pp. 207-216, <http://www.sciencedirect.com/science/article/pii/S0303243414001640>.

Grigorescu, I, Kucsicsa, G, Popovici, E-A, Mitrică, B, Mocanu, I, \& Dumitraşcu, M 2019, 'Modelling land use/cover change to assess future urban sprawl in Romania', Geocarto International, pp. 1-19, <https://doi.org/10.1080/10106049.2019.1624981>.

Hamdy, O, Zhao, S, Osman, T, Salheen, M, \& Eid, Y 2016, 'Applying a Hybrid Model of Markov Chain and Logistic Regression to Identify Future Urban Sprawl in Abouelreesh, Aswan: A Case Study', Geosciences, 
vol. 6, no. 4, p. 43, <http://www.mdpi.com/2076-3263/6/4/43>.

Idowu, TE, Waswa, RM, Lasisi, K, Nyadawa, M, \& Okumu, V 2020, 'Object-based multi-temporal land use land cover change detection of the coastal city of Lagos, Nigeria using post-classification comparison technique', South African Journal of Geomatics, vol. 9, no. 2.

Idowu, TE \& Home, PG 2015, 'Probable Effects of Sea Level Rise and Land Reclamation Activities on Coastlines and Wetlands', in, The 2015 JKUAT Scientific Conference, JKUAT, Nairobi, pp.207-220, <http://journals.jkuat.ac.ke/index.php/jscp/article/view/1251/1028>.

Idowu, TE, Nyadawa, M, \& K'Orowe, MO 2017, 'Hydrogeochemical assessment of a coastal aquifer using statistical and geospatial techniques: case study of Mombasa North Coast, Kenya', Environmental Earth Sciences, vol. 76, no. 12, p. 422, <http://dx.doi.org/10.1007/s12665-017-6738-y>.

Jat, MK, Choudhary, M, \& Saxena, A 2017, 'Application of geo-spatial techniques and cellular automata for modelling urban growth of a heterogeneous urban fringe', The Egyptian Journal of Remote Sensing and Space Science, vol. 20, no. 2, pp. 223-241, <http://www.sciencedirect.com/science/article/pii/S1110982317300352>.

Khoi, DD \& Murayama, Y 2010, 'Forecasting areas vulnerable to forest conversion in the tam Dao National Park region, Vietnam', Remote Sensing, vol. 2, no. 5, pp. 1249-1272.

Kumar, KS, Valasala, NVASS, Subrahmanyam, JV V, Mallampati, M, Shaik, K, \& Ekkirala, P 2015, 'Prediction of Future Land Use Land Cover Changes of Vijayawada City Using Remote Sensing and Gis', International Journal of Innovative Research in Advanced Engineering (IJIRAE), vol. 2, no. 3, pp. 91-97.

Li, M, Zhang, Z, Seen, D Lo, Sun, J, \& Zhao, X 2016, 'Spatiotemporal characteristics of urban sprawl in Chinese port cities from 1979 to 2013', Sustainability (Switzerland), vol. 8, no. 11.

Mahmoud, MI, Duker, A, Conrad, C, Thiel, M, \& Ahmad, HS 2016, 'Analysis of settlement expansion and urban growth modelling using geoinformation for assessing potential impacts of urbanization on climate in Abuja City, Nigeria', Remote Sensing, vol. 8, no. 3.

McPhearson, T, Parnell, S, Simon, D, Gaffney, O, Elmqvist, T, Bai, X, Roberts, D, \& Revi, A 2016, 'Scientists must have a say in the future of cities', Nature.

Megahed, Y, Cabral, P, Silva, J, \& Caetano, M 2015, 'Land Cover Mapping Analysis and Urban Growth Modelling Using Remote Sensing Techniques in Greater Cairo Region-Egypt', ISPRS International Journal of GeoInformation, vol. 4, no. 3, pp. 1750-1769, <http://www.mdpi.com/2220-9964/4/3/1750/>.

Mishra, V, Rai, P, \& Mohan, K 2014, 'Prediction of land use changes based on land change modeler (LCM) using remote sensing: A case study of Muzaffarpur (Bihar), India', Journal of the Geographical Institute Jovan Cvijic, SASA, vol. 64, no. 1, pp. 111-127, <http://www.doiserbia.nb.rs/Article.aspx?ID=0350$75991401111 \mathrm{M}>$.

MPPUD 2016, Lagos State - Basic Facts, Ministry Of Physical Planing And Urban Development - Lagos State, viewed 13 May 2020, <https://physicalplanning.lg.gov.ng/who-we-are/lagos-state-basic-facts/>.

Opoko, AP, Oluwatayo, A, Opoko, AP, \& Oluwatayo, A 2014, 'Trends in Urbanisation: Implication for Planning and Low-Income Housing Delivery in Lagos, Nigeria’, Architecture Research, vol. 4, no. 1A, pp. 15-26.

Owoeye, JO \& Popoola, OO 2017, 'Predicting urban sprawl and land use changes in Akure region using markov chains modeling', Journal of Geography and Regional Planning, vol. 10, no. 7, pp. 197-207.

Showstack, R 2014, 'Scientists focus on land subsidence impacts on coastal and delta cities', Eos, vol. 95, no. 19, p. 159.

Tayyebi, A \& Pijanowski, BC 2014, 'Modeling multiple land use changes using ANN, CART and MARS: Comparing tradeoffs in goodness of fit and explanatory power of data mining tools', International Journal of Applied Earth Observation and Geoinformation, vol. 28, no. 1, pp. 102-116.

Tewolde, MG \& Cabral, P 2011, 'Urban sprawl analysis and modeling in Asmara, Eritrea', Remote Sensing, vol. 3, 
no. 10 , pp. $2148-2165$.

The World Bank 2019, Population growth (annual \%) - Nigeria, The World Bank Group, viewed 13 May 2020 , <https://data.worldbank.org/indicator/SP.POP.GROW?locations=NG>.

UN 2017, 'Progress towards the Sustainable Development Goals. Report of the Secretary-General. E/2017/66', Report of the Secretary-General, vol. E/2017/66, no. 11 May, p. 19, <https://unstats.un.org/sdgs/files/report/2017/secretary-general-sdg-report-2017--EN.pdf>.

UNDESA 2018, World Urbanization Prospects: The 2018 Revision, United Nations Department of Economic and Social Affairs.

United Nations 2014, World's population increasingly urban with more than half living in urban areas, UN DESA, viewed 24 November 2017, <http://www.un.org/en/development/desa/news/population/world-urbanizationprospects-2014.html>.

USGS 2017, Shuttle Radar Topography Mission (SRTM) 1 Arc-Second Global, viewed 18 March 2017, <https://lta.cr.usgs.gov/SRTM1Arc>.

USGS 2020, EarthExplorer - Home, United States Geological Survey, viewed 14 May 2020, $<$ https://earthexplorer.usgs.gov/>.

Verburg, PH, Schot, PP, Dijst, MJ, \& Veldkamp, A 2004, 'Land use change modelling: Current practice and research priorities', GeoJournal, vol. 61, no. 4, pp. 309-324.

Verburg, PH \& Overmars, KP 2009, 'Combining top-down and bottom-up dynamics in land use modeling: Exploring the future of abandoned farmlands in Europe with the Dyna-CLUE model', Landscape Ecology, vol. 24, no. 9, pp. 1167-1181.

Wang, J \& Maduako, IN 2018, 'Spatio-temporal urban growth dynamics of Lagos Metropolitan Region of Nigeria based on Hybrid methods for LULC modeling and prediction', European Journal of Remote Sensing, vol. 51, no. 1, pp. 251-265, <https://doi.org/10.1080/22797254.2017.1419831>.

WHO 2010,'The Rise of Modern Cities', in, Hidden Cities: Unmasking and Overcoming Health Inequities in Urban Settings, pp.3-10.

Wong, PP, Losada, IJ, Gattuso, J-P, Hinkel, J, Khattabi, A, McInnes, KL, Saito, Y, \& Sallenger, A 2014, 'Coastal systems and low-lying areas.', in, Climate Change 2014: Impacts, Adaptation, and Vulnerability. Part A: Global and Sectoral Aspects., Contribution of Working Group II to the Fifth Assessment Report of the Intergovernmental Panel on Climate Change, New York, NY, USA, pp.361-409.

Worldometers 2019, Population of Nigeria (2019 and historical), viewed 11 May 2019, <https://www.worldometers.info/world-population/nigeria-population/>.

Yirsaw, E, Wu, W, Shi, X, Temesgen, H, \& Bekele, B 2017, 'Land Use/Land Cover Change Modeling and the Prediction of Subsequent Changes in Ecosystem Service Values in a Coastal Area of China, the Su-XiChang Region', Sustainability, vol. 9, no. 7, p. 1204, <http://www.mdpi.com/2071-1050/9/7/1204>. 